DOI: $10.15503 /$ jecs20162.131.149

\title{
SIGNIFICANT ARTIFACTS IN SCHOOLS: TEACHER AND PUPIL PERSPECTIVES
}

\author{
SANDRA KAIRE \\ Faculty of Philosophy, Vilnius University, \\ Universiteto str. 9/1, LT-01513, Vilnius, Lithuania \\ E-mail address: sandra.kaire@fsf.vu.lt
}

\begin{abstract}
Drawing on the recent research 'Dominant and demotic school culture: analysis of tensions fields' this paper analyses found artifacts in 6 different Lithuanian secondary schools. The visual data was collected by making images of places and artifacts which were mentioned during the walks in the school territory with one teacher and one pupil afterwards. The analysis of images focuses particularly on two aspects: a) which artifacts are significant for teachers and pupils in the schools? b) What do these artifacts mean for teachers and pupils? Therefore, the analysis is based on comparing walks among teachers and pupils in all schools. The analysis shows obvious differences on re/presented artifacts among teachers and pupils. The teachers emphasized and showed those artifacts which on one way or another represent their schools' achievements, like pupils' sport achievements, pupils' artworks, and honored pupils' displays, and were related with aspects of pride. The paper argues the possible reasons for the importance of pride in schools. Meanwhile, pupils were highlighting spaces they like to gather around during non-learning time. Pupils appreciate less visible places because it is possible to have some privacy there. As analysis shows, different sitting artifacts (chairs, sofas, beanbags) play an important role for creating such private pupils' 'oases'. On the other hand, such artifacts, as pupils' artworks, information displays, and sport achievements, seem to be meaningful for pupils if they were contributing in the creation process or were mentioned in these artifacts.
\end{abstract}

Key words: school culture, school artifacts, teacher, pupil, pride and privacy.

\section{INTRODUCTION}

By going into the school territory, one's eyes first capture the different spaces as the physical school environment, school building and its architecture. Later we notice other visible objects like pupils' artwork, sports awards, information displays which can be found in school areas, hallways, corridors, locker-rooms and classrooms. All these artifacts are part of everyday school life and routine which can make schools "either meaningful sanctuaries for students and celebrations of accomplishment or dead and 
empty vessels of bureaucratic control" (Deal and Peterson, 2009, p. 34). Artifacts express and reflect values and cultural patterns (Prosser, 2007); therefore, they are more than neutral visible products in schools. Artifacts in schools become signs and symbols, routines and rules which give a meaning in everyday school life.

Hearn and Thomson (2014) define artifacts as objects which "are made by someone somewhere, for a particular purpose, and are framed by social conventions and involve taken for granted ways of doing things" (p. 156). Therefore, we could say that existing artifacts in schools have their particular purpose. Moreover, visible artifacts in different schools might have a different purpose. For instance, school leaders can build and adapt artifacts, such as daily schedules, meeting agendas to shape instructional practices (Halverson, 2003; 2007), or artifacts, such as school uniforms, pupils' sport achievements, and pupils' artwork can be related with pride and cultural cohesion in schools (Deal, Peterson, 2009), or gendered performances (O'Donaghue, 2006, 2007; Happel, 2013), or control and power structures (Gordon,\& Lahelma, 1996; Huss, 2007).

As Hall (1997) stated, culture primarily is concerned with the production and exchange of meanings between members of the group. "Thus culture depends on its participants interpreting meaningfully what is around them, and 'making sense' of the world, in broadly similar ways" (Hall, 1997, p. 2). But things in culture rarely have single, fixed and unchanged meaning, and the members of culture are those who are giving meaning to people, objects and events. A meaning for objects, people and events can be given in different ways: by frameworks of interpretation members bring to objects; by how members use or integrate things into everyday practice; or by how these things are represented by members (Hall, 1997). Therefore, when we speak about school culture it also becomes important to understand how school community members interpret existing artifacts in schools, how artifacts are used in everyday school life, which artifacts 'make sense' in schools, and what meanings they have to different members of the school community. Analysis of artifacts in the paper focuses on understanding which artifacts are significant for teachers and pupils in schools and what meanings these existing school artifacts have in Lithuanian secondary schools. Moreover, the visual data in the paper is analyzed by comparing walks among teachers and pupils and seeking to understand whether these meanings, which pupils and teachers give to existing artifacts in schools, have similarities. The comparison of walks among teachers and pupils also contribute to discover if existing school culture is either homogenous or a result of different interactions of existing subcultures in schools.

Moreover, by understanding what meanings visible culture in a school have, it is also possible to get closer into the unseen school culture (Prosser, 2007). Lately, an accomplished analysis (Survutaite, 2015) on evaluations (2008-2012) of Lithuanian school performance quality revealed that external experts easily capture and describe visible school culture in schools, such 
as behavior, traditions, rituals, and symbols. Survutaite (2015) remarks that even though external experts in reports describe a broadly visible school culture, there is a lack of thorough analysis of visible school culture and information about the unseen school culture, such as school beliefs, underlying assumptions, etc. As the level of artifacts in the organizational culture is both easy to observe and very difficult to decipher (Schein, 2010), it becomes dangerous to infer the schools' cultures by focusing only on visible artifacts. Therefore, the paper seeks also to look more deeply into existing artifacts in Lithuanian schools and 'see' what existing cultural artifacts in schools say about the unseen school culture. Thus, as in the Lithuanian context there is nearly no research undertaken on school artifacts, the paper seeks to broaden the research field on school culture in Lithuania.

\section{THE STUDY}

The papers focus particularly on analyzing found artifacts in Lithuanian schools while researching Lithuanian secondary school culture ${ }^{1}$. Drawing on recently accomplished research in Lithuanian secondary schools, 'Dominant and demotic school culture: analysis of tension fields', that was based on poststructural methodology and characterized by ethnographic sensibility, the paper analyses visual artifacts photographed during the walks with 6 teachers and 6 last grade pupils (11 ${ }^{\text {th }}$ and $12^{\text {th }}$ grades). The artifact images were made in 6 Lithuanian secondary schools ${ }^{2}$. The school artifacts were photographed during walks on school grounds individually with one teacher and with one pupil afterwards. The only criterion for a selection of the teacher and a pupil for a walk were to be willing to show the school territory. However, it is important to point out that usually head teachers in schools selected the person with whom to walk. More details will be discussed in the following sections of the paper.

Visual data collection of school artifacts has been chosen following Prosser's and Warburton's (1999) idea that: "Amongst other things, visual sociology records visual elements that represent the underlying assumptions of participants. These underlying assumptions are the foundations of the culture of a school. In raising questions about the significance of these images of participants, such as teachers and pupils, people are helped to confront

1 The paper is written while conducting the research project 'Dominant and demotic school cultures: Analysis of tension fields', financed by the Research Council of Lithuania (2014-2015, registration No. MIP-074/2014).

2 The research was performed in three different municipalities of Lithuania: Kaunas, Klaipeda and Vilnius. For research in each municipality two schools were chosen: one in a town area, one in a rural area. All secondary schools have gymnasium status. However, two schools (Vilnius and Kaunas town) implemented only secondary lower education (i.e. part II, implemented in the $9^{\text {th }}-10^{\text {th }}$ grades, which in gymnasiums are named as $1^{\text {st }}$ and $2^{\text {nd }}$ forms) and secondary upper education. Other 4 gymnasiums implemented primary, lower secondary and upper secondary (the school in Vilnius rural area; the school in Kaunas rural area, the school in Klaipeda town and the school in Klaipeda rural area). 
their cultural assumptions which in turn and where necessary, allows them to begin to change school culture" (p. 14).

The starting question for the walk with the teacher and pupils was, "What would you like to show us in your school?" During the walks in the school grounds the researcher followed a teacher and a pupil without imposing any directions or objects to be shown; the pupil and teacher could show any place and any objects they thought were important to see in the school. The images were taken by the researcher in the places or into objects which the teacher and pupil showed. Therefore, the images were taken only of those artifacts and places which the walkers mentioned and even though there could be a lot of different artifacts around, the images were taken only on that object or in that place that was mentioned.

As Schein (2010) emphasized, the level of artifacts in the organizational culture is both easy to observe and very difficult to decipher, for this reason, the chosen 'walk and talk' method (Prosser, 2007) shifted data collection from research 'on' to research 'with' and 'by' pupils and teachers. As a result in some moments during the walk the researcher asked some additional questions ("Why is this place/artifact significant for you?" "What does this artifact mean for you?" etc.) in order to get more information about what meanings those significant artifacts have for a teacher or pupil in each school. Therefore, for the artifact analysis, researcher observations and extracts of other interviews made during research with school administration, teachers, and pupils, are also used.

Because a lot of different places and artifacts were shown during walks, image selection and analysis were based on searching for common significant artifacts in all schools among teachers and pupils: i.e., common significant artifacts which teachers mentioned during walks and common significant artifacts which pupils mentioned in all schools. To this end, artifact analysis and comparison in the paper is divided into two sections: walks with teachers and walks with pupils.

\section{'THIS IS OUR PRIDE': WALKS WITH TEACHERS}

The walk with the teacher in the first school (S1) ${ }^{3}$ starts from the head teacher's cabinet. It is important to mention that before the walk the head teacher and a teacher we walked with were having a small conversation about the places to be shown during the walk. The head teacher mentions a few for teachers that should be shown during the walk. It does suppose that agreements and orders from a person in a higher position in the school are important and should be made. Moreover, in the majority of schools (S2, S3, S4, S5) usually one of the school deputies or the head teacher (S6) was sho-

3 Given codes for the schools: $\mathbf{S}$ means school; number (from $\mathbf{1}$ to $\mathbf{6}$ ) means the visiting sequence in each school during research; S1, S2, S3, S4, S5, S6. Codes for talks and interview extracts: talk and/or interview with a teacher - T, talk or interview with a head teacher - HD, talk or interview with a pupil $-\mathbf{P}$. 
wing the school territory. It seemed that school (re)presentation is entrusted to people who are involved in school administration. Even though during individual interviews head teachers emphasized that all community members (head teacher, teachers, pupils and also parents) are founders and shapers of school culture, there was nonetheless a feeling that the head teachers' words and orders are most important. As Schein (2010) explains: "The connection between culture and leadership is clearest in organizational cultures and microcultures. What we end up calling a culture in such systems is usually the result of the embedding of what a founder or leader has imposed on a group that has worked out. In this sense, culture is ultimately created, embedded, evolved, and ultimately manipulated by leaders... These dynamic processes of culture creation and management are the essence of leadership and make you realize that leadership and culture are two sides of the same coin" (p.3).

Prosser

(2007) also stated that head teachers are key shapers of school culture; therefore, even though during in-depth interviews head teachers maintained that the whole community creates the school culture, their role was essential in creating and shaping school culture in the analyzed Lithuanian secondary schools.

The foremost place the teacher in the first school (S1) takes us to is the school hallway with many different artifacts: a display of pupils' sport achievements, pupils' artwork, graduates' farewell gifts, and a television set. It seems that the hallway and corridors are a heart

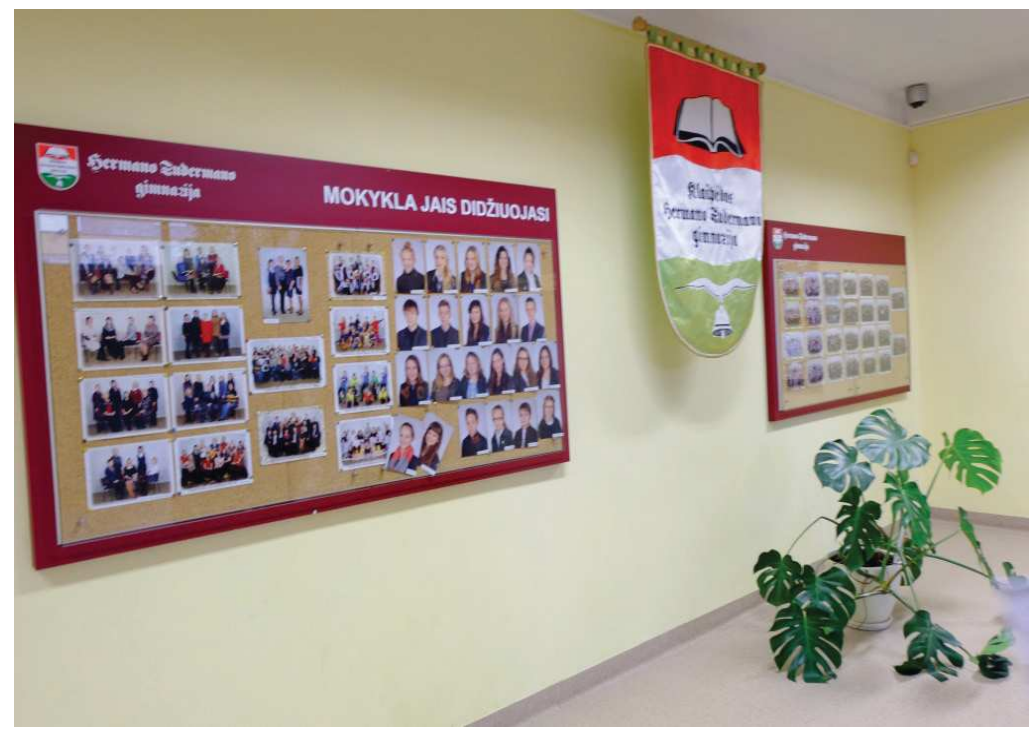

Figure 1. Display with honored pupils in the school (S3)

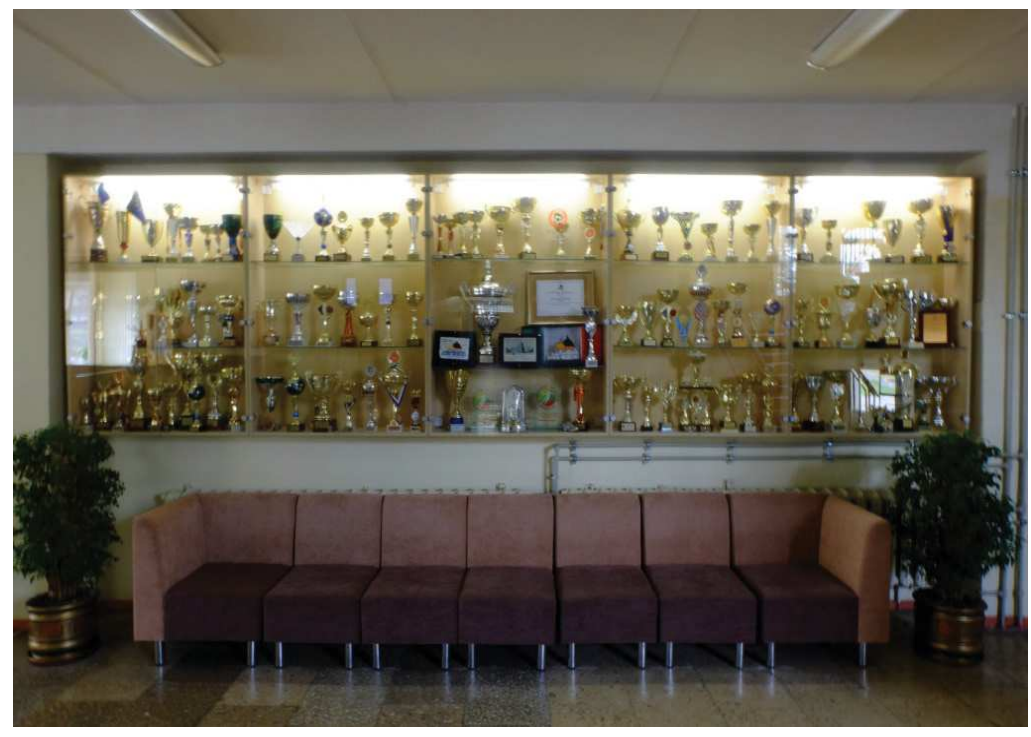

Figure 2. Pupils' sport achievements and graduate pupils' farewell gift (sofa - S.K.) in the school (S1) 
and the main representational place in the majority of schools (S1, S3, S4, and S5). In the images below we see that important things are put into the most visible and busy place of schools - in hallways and corridors.

While teacher (S1) shows pupils' sport achievements, she says "This is our pride" (S1-T) that actually expresses what the school values are and what it has to show. In another school a teacher (S3) shows a display with the best pupils' images and also says "We are proud of them" (S3-T). Pride seems to be a very important representational factor in each school which also contributes to reveal the uniqueness and exclusiveness of a school. It is important to note that in schools teachers usually mentioned the displays of pupils' sport achievements (S1, S2, S3, S5, S6), displays with honored pupils (S1, S2, S3, S4, S5, S6), and participation in the international projects $(S 2, S 4, S 6)$ that express the pride and value of athletic competition and academic success of pupils, as well as the activeness of schools. By the same token, not only were sport and academic achievements mentioned, but also pupils' artwork by teachers often during walks. School hallways, corridors and classrooms shown during walks were often full of pupils' artwork (S1, S3, S5). It is important to note that even in some schools creativity was not officially declared as a value, but nonetheless the hallways and corridors looked like "galleries celebrating pupils' creativity and accomplishment" (Deal, Peterson, 2009, p. 34). Moreover, during walks teachers mostly showed those classrooms (usually only a few classrooms were shown) which

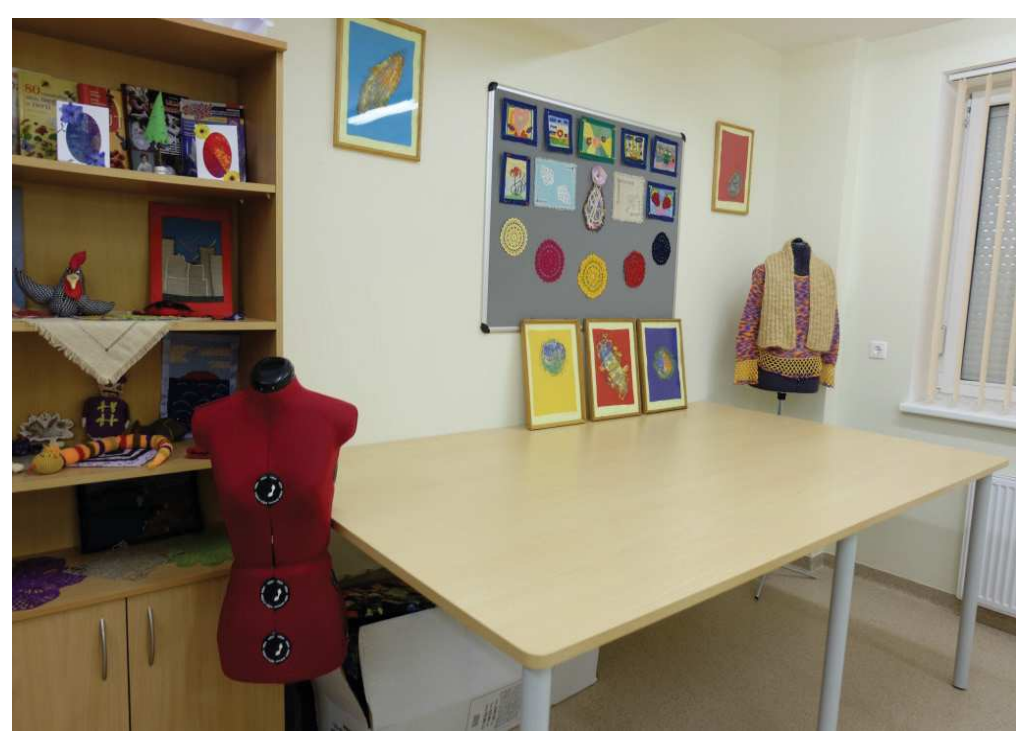

Figure 3. Pupils' artwork in technology classroom (S2)

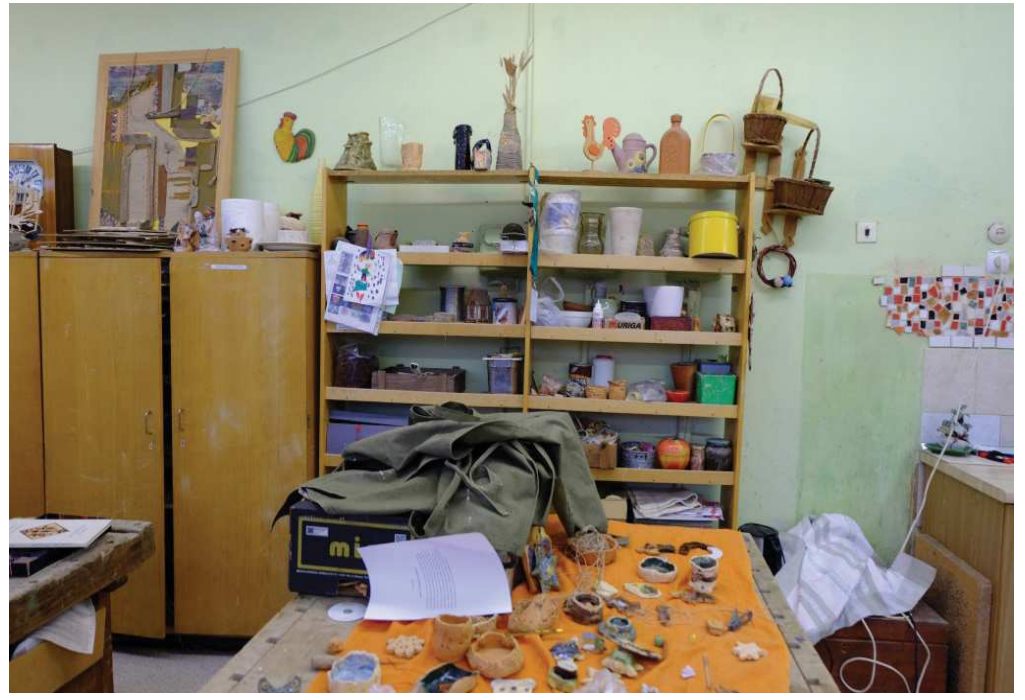

Figure 4. Pupils' ceramics artwork in technology classroom (S3) 
were full of different pupils' artwork. Thus, these artifacts as appear to be symbols which, according to Deal and Peterson (2009), represent what the schools stand for and play a powerful role in cultural cohesion and pride.

Moreover, exhibited artifacts in schools in a way demonstrate how much visual arts are significant in schools. In the schools (S1, S3, S4) visual arts or technologies teachers emphasized it and it was evident they had great role to decorate schools as also to represent pupils' creativity. Nonetheless, there was a school (S6) where performing arts, like music and dance were mentioned much more; therefore, it was noticeable that in the school there was much less pupils' artwork. We could say that in all schools arts and technologies teachers were significant creators of artifacts, but it was clearly noticeable that in the last school (S6) pupil's creativity was shown in other ways. As the head teacher also mentioned during the walk: "We have such a great music teacher. I would go with her even to the war...Any time she has performances with children, they (pupils -S. K.) do incredible things" (S6-HT).

Graduate pupils' memorial pictures and/or testaments and/or farewell gifts are important parts of a school's 'unwritten' traditions that schools (S1, S2, S5, S6)

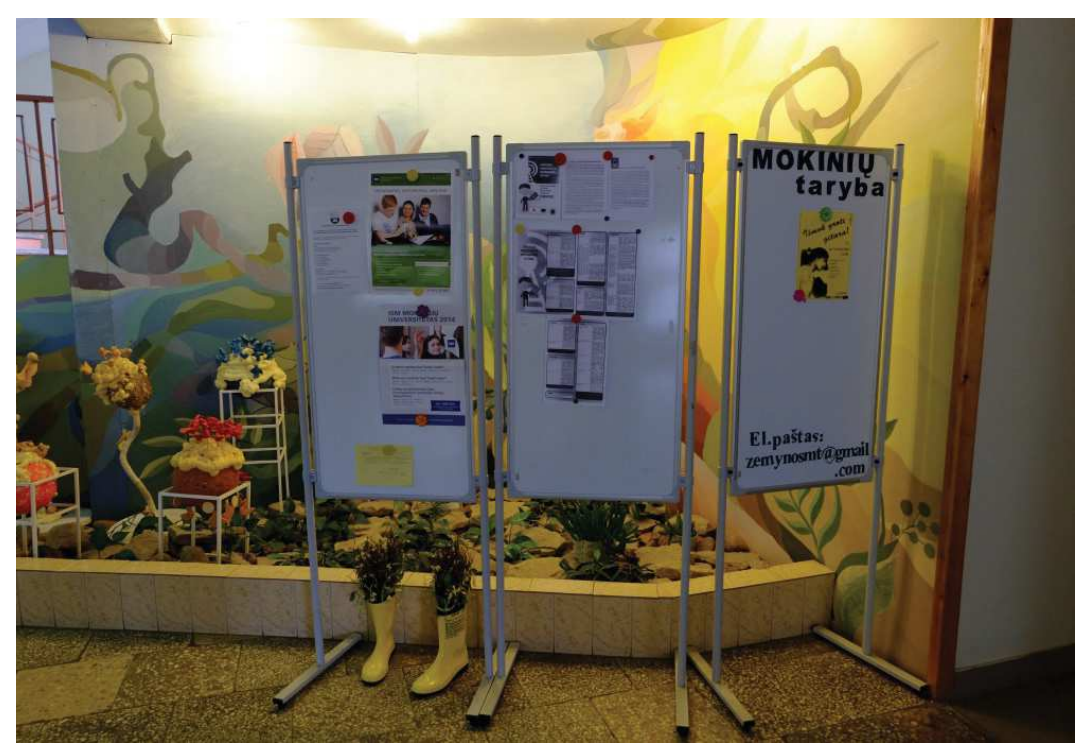

Figure 5. Information display and shoes with testaappreciate and are

also proud of. Especially in the first school (S1) there was great attention given to graduate pupils' farewell presents. It is important to note that these presents were usually put in visible and busy areas of the school, and were actually practical and usable in daily school life. Already in a hallway there is a sofa, an information display and brick on the ground which different generations of graduate pupils left for the school (images $2,5,6)$.

Figure 6. The brick graduate pupils presented for school (S1)

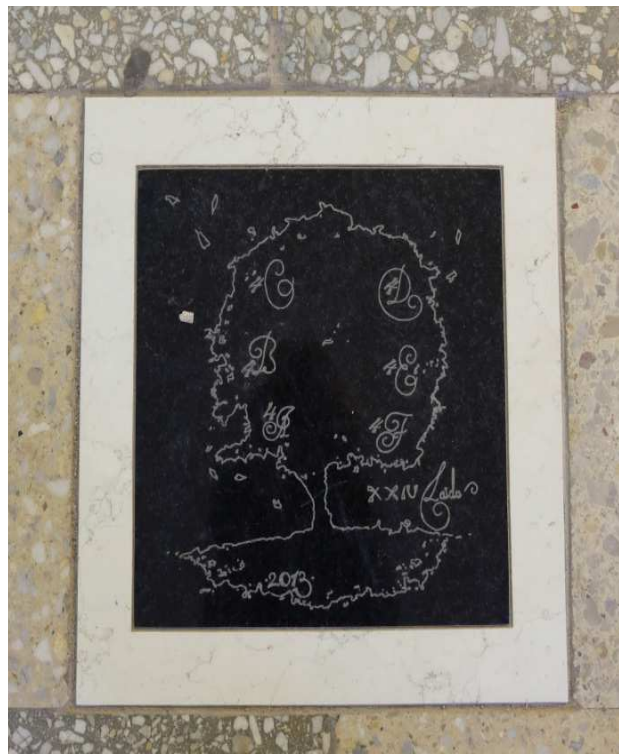


In other schools (S2, S3, S6) teachers mentioned testaments, pictures and other symbolic things which graduate pupils leave for schools. It seems that the vividness and extent of this tradition in a way also depends on how much it is supported by the school community, head teachers, pupils etc. For example, a board with pens and testament (image 7) was presented by the graduate class (class from the 2012-2013 school year) for the future graduates. Pens are intended to be as a present for future graduates, as graduate pupils wrote in the testament, "They (pens - S. K.) will be useful in the exam period for you and, we hope, will bring you luck." However, this present is put in the school's museum and as we see in the image, the pens actually were not taken. Also in the last school (S6), the head teacher showed pictures which the graduate pupils' generation are leaving for the school (image 8) and commented: "If pupils' are not lazy, they do these pictures and leave them for the school... But I am against material presents for the school" (S6-HT).

During walks teachers also often mentioned the student council and its activities in school daily life. Student councils are

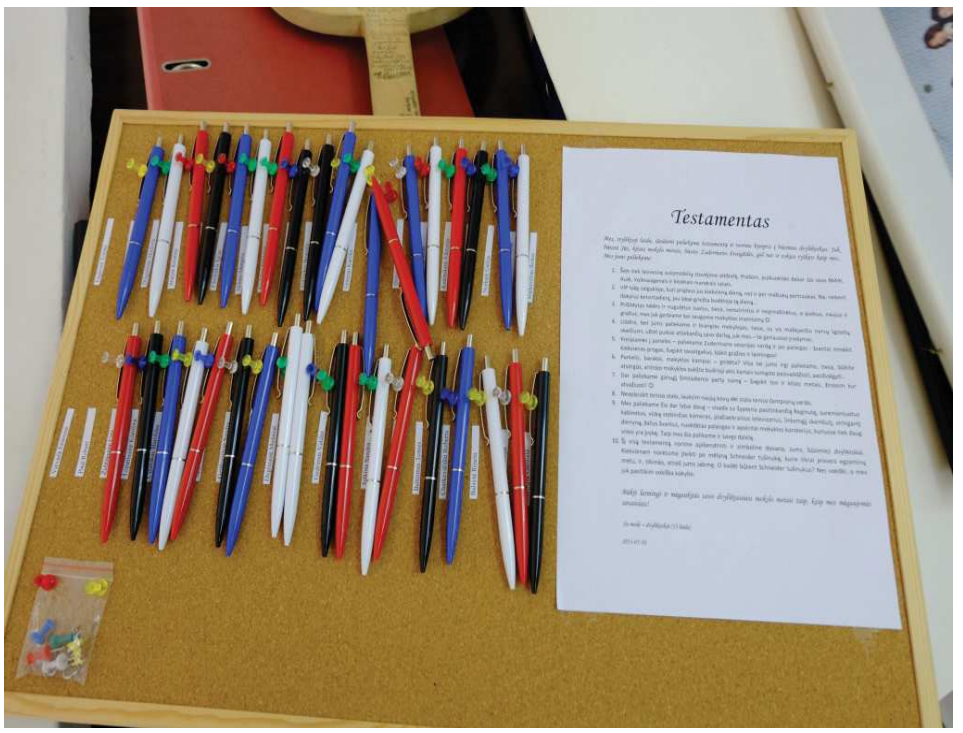

Figure 7. Board with pens and testament which were presented by graduate pupils for future graduates (S3) part of the autonomous institution in Lithuanian schools and have a significant role to represent pupils' interests in schools. The student council can also be involved in school management, as one pupil during the walk commented: "As a member of the student council I have some relations with school authorities" (S2-P). Moreover, in many schools (S1, S5, S6) the student council is an active organism to organize different official and non-formal events. In some

Figure 8. Graduate pupils draw pictures and leave them as a present for the school (S6)

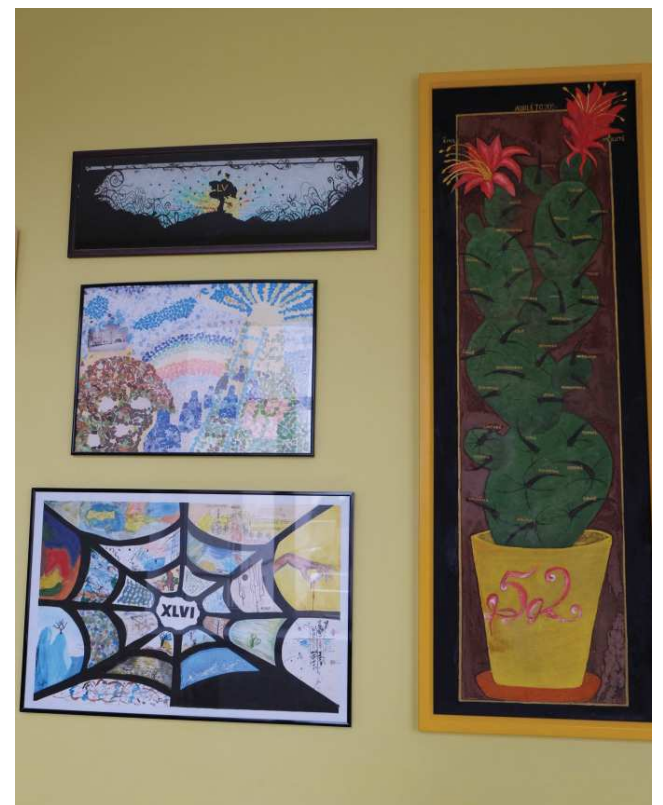


schools the student council is even responsible for ensuring discipline and order (S3). Members of the student council might also have other 'privileges' which will be mentioned in the next section of the paper. It is important to note that the student council often has private places to gather and organize meetings in school and their activities are usually coordinated by one of the schools' deputies (S1, S5, S6). In some schools (S1, S5), teachers mentioned that the student council meets in one of the school deputies' office. Thus, we could say that on the one hand the student council is actually close to the school administration and knows more information about what is happening in schools, and therefore might be more entrusted to represent school, as it was made during walks when usually in most schools one pupil from the student council was delegated to show the school territory. On the other hand, we could say that the student council might be used in a way by the school administration for control and to ensure that interests of school administration are represented.

During the walk in one school (S1), the teacher put great focus on the place where members of the student council meet. In the image (below) we see a deputy table (next to the window) and the round table, which 'belong' to the pupils who gather there.

Around the table there are some chairs, cups for tea, and a flower - artifacts that are common in offices, but it is also important to mention that pupils here have their information display and place in a cupboard to keep some things and food. From one side we do see that there is nothing really exclusive there, but from the other side it is clear that these artifacts create a space where pupils can be in a group. Pupils there even created two different types of rules: ones intended to regulate the behaviour in the office (to knock before entering the office, close the doors after entering or leaving, wash the dishes and clean the table, etc.) and others are intended to regulate the meetings of the student council (speak one by one, do not make a noise during meetings, etc.). It seems that in this deputies' office there originates a really autonomous organism with its own rules and its own place. The teacher we walked into this office with described it as: "It is the office of the school deputy who is responsible for after-school activities in school and here is also a pupils' oasis...

Figure 9. The office of school deputy who is responsible for after-school activities (S1)

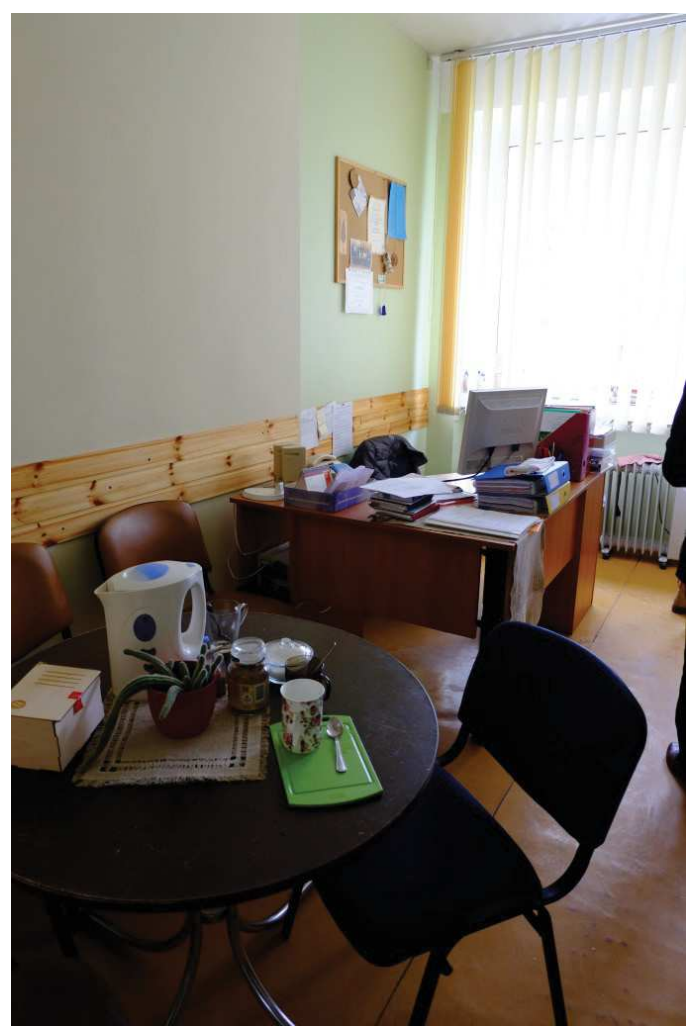


Mostly here come pupils from the student council and those pupils who are organizing school events. But other pupils can come too" (S1-T).

Let us look into the meaning of word oasis. Oasis can be described as a "small fertile or green area in a desert region, usually having a spring or well", or as "something serving as a pleasant relief, refuge, or change from the usual, the annoying, or the difficult" (Webster's New Universal Unabridged Dictionary, 1994, p. 992). Therefore, the metaphor the teacher uses by presenting this place might imply that this office for pupils is like a refreshing spot, and change from the usual, even difficult and annoying everyday school life. It might even be supposed that this place is like a 'green place' which helps pupils find relief and feel pleasant. While we were still in the office the school bell rang and pupils (most who belong to the student council) started to gather. We asked pupils why they liked this place. One of them said, "Here it is calm, here it is cozy and safe. Here it is like an exclusion from the school, like your room" (S1-P1) and the other pupil adds, "Here you can find other persons who share the same worldview because maybe in your class you do not have many classmates with the same worldview. Here you come to talk" (S1-P2). It seems that actually here pupils can 'escape' from everyday school life, to move away from the control and monitoring and moreover here they can create some privacy. Besides that, this place creates a kind of 'private affinity club' as the pupils who come here most are those who belong to the student council and those who are involved in school event organizing. The pupil we walked with afterwards in the same school (S1) also mentioned that she as a student council member has a privilege to stay in this office. As we will see from walks with pupils in the schools, in one or another way pupils seek to find some relaxing places and privacy. However, it appears that those pupils who do not belong to 'official' groups, like the student council or events organizing groups, choose more neutral school places to gather. Moreover, it seems that the teachers' personality and relationship that teacher creates with pupils are other factors which gather some pupils into different groups. As one of the deputies commented while we were in the office: "Different (teachers - S. K.) personalities tug at different pupils. Some pupils will come just to my office, some pupils just to other teachers' offices... And when there is a relationship with pupils, the pupils become as support, they protect you and appreciate you. You are protected by these pupils. They are protecting you from all that system and regulations. Everything goes forth from this relationship" (S1-T).

Exhibited artifacts illustrate the powerful role of pride in school culture which herewith relate schools with each other and also unify them. It is important to note that a majority of the investigated schools (S1, S3, S4, S5, S6) have a long history ${ }^{4}$ which was noticeable in schools by different artifacts too. According to Deal and Peterson (2009), the history and tradi-

4 The schools S2 and S3 were established 23 years ago, and S1 28 years ago. Schools S4, S5, and S6 have especially long histories: school S5 was established 92 years ago, and schools S4 and S5 have a history of over 200 years. 
tions of a school are important symbols of longevity and sustained purpose. Therefore, schools without a clear sense of history are rootless and lack meaning. School history plays an important role in identifying and shaping school culture too. According to Schein (2010), matured organization: "...develops a self-image, an organizational "face" so to speak, that will be built around the best things they do. Organizations, like individuals, have a need for self-esteem and pride so it is not unusual for them to begin to claim to be what they aspire to be, while their actual practices are more responsive to the realities of getting their primary task accomplished" (p. 290). With reference to Schein's ideas it is possible to state that pride (possibly also self-esteem) in these schools is formed naturally because of a sense of long school history.

Another important thing that might imply the importance of pride in schools is a practice of external evaluations of Lithuanian schools' work quality. The goal of external evaluation is to promote the improvement of schools and the better achievements of pupils. The evaluation focuses on lesson observations and analysis of processes ongoing in schools (National Agency for School Evaluation, 2015). During walks some teachers (S5, S6) mentioned that schools had external evaluation and they were sharing some experiences and were stressing what was valued by the external experts as the schools' strengths. Moreover, during research it was noticeable that in some moments the school administration and teachers which showed the schools were looking into researchers like into 'inspectors'; often someone from the school administration accompanied us, were organizing meetings and interviews with pupils, etc. Therefore, pride might become a way for schools to show up in a good way, on what schools have and make best, but not actually to open themselves up and to show the reality of everyday school life.

\section{'WHAT SHOULD I SHOW YOU? PICTURES?': WALKS WITH PUPILS}

The walk with a pupil in the first school (S1) starts from one of the school deputies' offices. The first thing the pupil says to the researcher is the question: "What should I show you? Pictures?" As the researcher says to show anything that pupil would like to show us, she starts to get to the places that are important for pupils. It is interesting to note that in the same school before the walk, the teacher also had a small conversation with the head teacher on what to show. So it seems that orders and agreements with a 'higher position' person in the school community are important and should be made in one or another way. Moreover, as was mentioned before, usually in schools the head teacher or deputies selected the pupils, mostly from the student council, who would show the school territory. On the one hand, it might imply that assignments to do something are important in everyday school life and 
should be agreed with the head teacher or any other higher position person in schools. On the other hand it also shows that student councils in schools have significant roles in representing not only the pupils', but also the schools' administration interests.

In this walk as in other schools, pupils actually concentrated on showing places where pupils like to gather, stay and do things in groups. Looking into trajectories of the walks there is a great difference among teachers and pupils. As the teachers showed mostly representational places in schools, like hallways, classrooms that were full of pupils' artwork, events places, school library, staffrooms, etc., as well as representational artifacts, like pupils' sport achievements, artwork, and graduate pupils' farewell presents for school, pupils focused more on neutral, non-teaching and non-learning places. As Gordon and Lahelma (1996) had discovered in their research, pupils in schools are often in full view of others and are subjects to be controlled and monitored. Because of this, a part of their activities in schools consists of trying to find ways and means to establish some privacy. It seems that in the investigated schools' part of pupils' activities also related with a search for privacy and in the corridors pupils always find places where they actually can get out of the spotlight. Pupils prefer less visible places

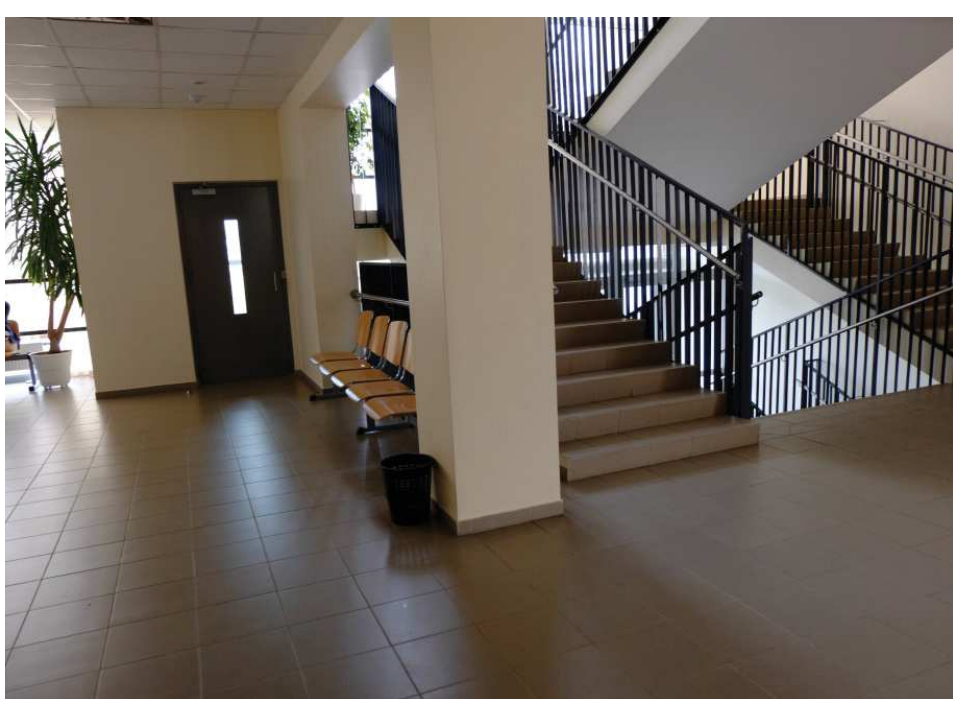

Figure 10. We (elderly pupils-S. K.) sit here because it is comfortable,

distant from teaching spaces and school administration places. Moreover, these places are also convenient for groups to gather and mostly there are some sitting things (like chairs, sofas etc.) that seem important for pupils. It seems that schools' corridors in many schools (S1, S2, S4, S5, S6) are the heart for pupils' movement and gathering.

Figure 11. Here is our (pupils' S. K.) comfort zone (S4) and here are good chairs and a beautiful environment (S3)

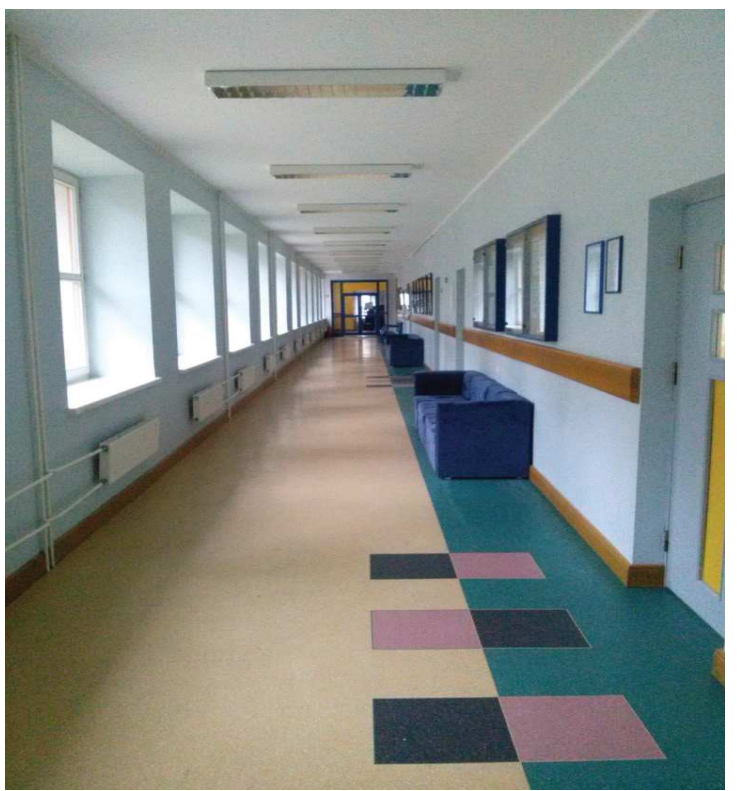


In the pictures above we see places where pupils like to gather and relax during breaks. In image 10 we see a hallway and some chairs next to the stairs where pupils like to gather. From one side it seems that it is a busy school place, but it is important to mention that in a way it is out of the spotlight because it is far away from the porters' place and

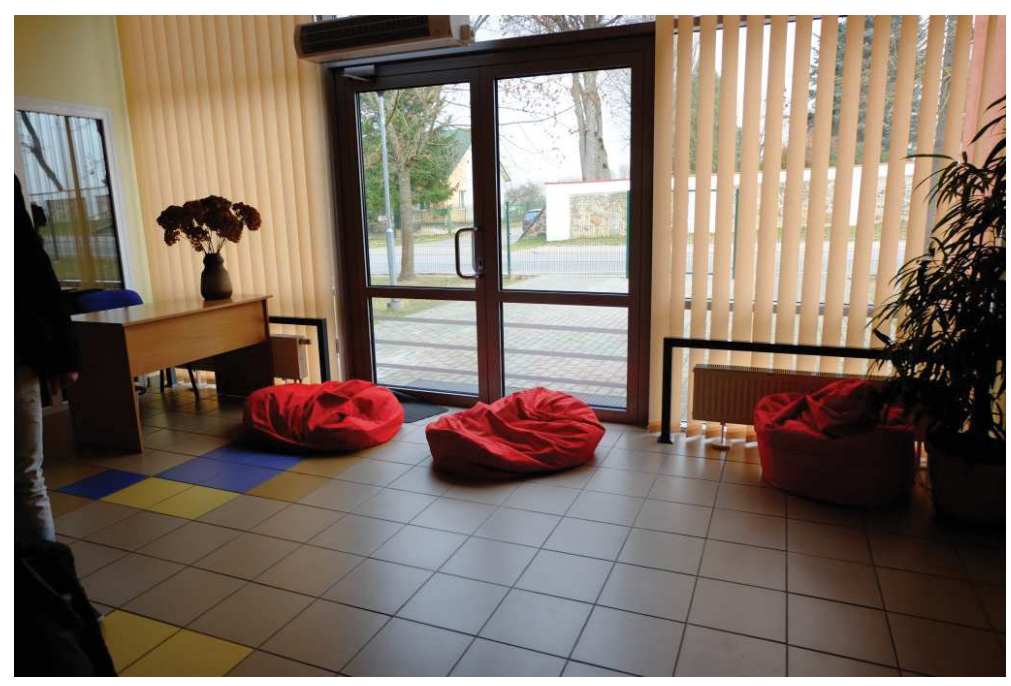

Figure 12. Beanbags that were presented to school by one of the graduate classes (S2) entrance doors. In the S4 school (image 11), again the pupils' comfort zone is in the corridor with sitting places where they can relax. It becomes obvious, that very important artifacts for pupils in the schools is seating. Moreover, one of the traditions that schools have and was mentioned in previous section is the presents from graduate generations as farewell gifts when leaving the school. During walks pupils (S1, S2, S5) mentioned and showed some farewell presents which graduate pupils had left. In actuality, most of the things pupils showed were related again with seating areas. The graduate class left a sofa (S1), lounges (S5), benches to sit outside (S1), or beanbags (S2, S5) as gifts.

It also in some way shows that for pupils it's important to have their space with sitting places which help to keep communication as well as to get some privacy in a school. As the pupil we walked with in the first school said, "We have a TV in the corridor, but actually it seems it is more important for teachers. And pupils are interested more to talk with each other" (S1-P).

School canteens were mentioned by a majority of pupils (S1, S2, S4, S5) during walks and seem to be one of the other favorite places where pupils like to gather and stay.

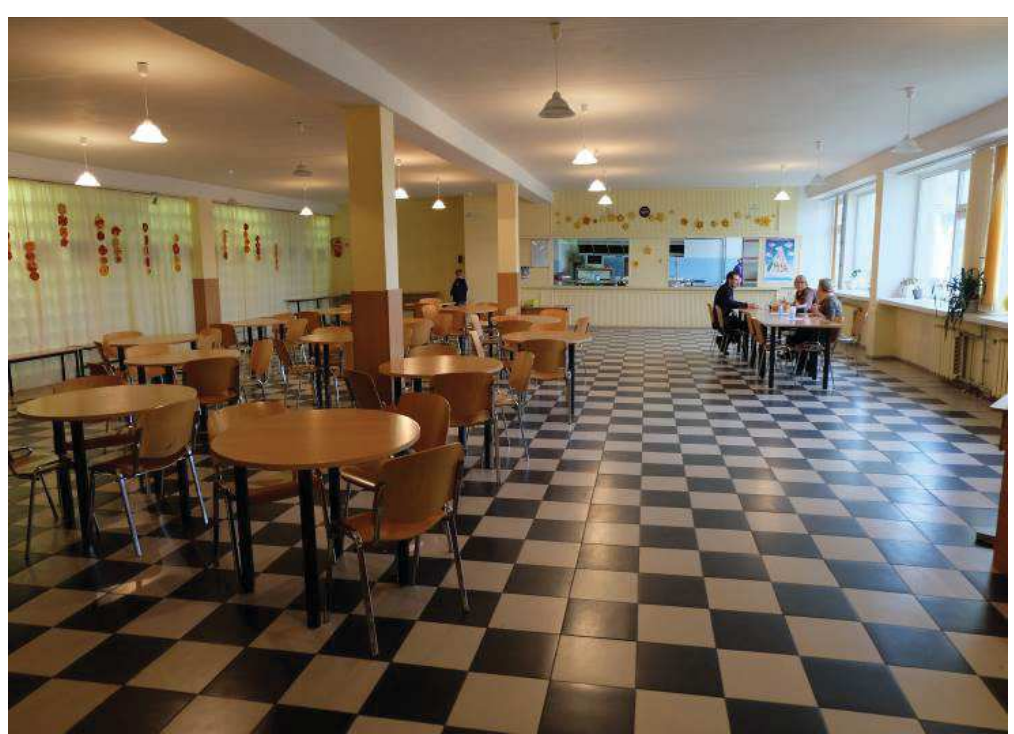

Figure 13. School canteen (S1) 
The main artifacts we see in the canteens (images above) are tables, chairs or benches - objects where pupils can sit, eat, chat with each other, etc. It is important to take a look at what seating arrangement these tables and chairs in the canteen form. As we see in the first canteen (image 13), there are round tables (one by one) with a few chairs around them that form a modular seating

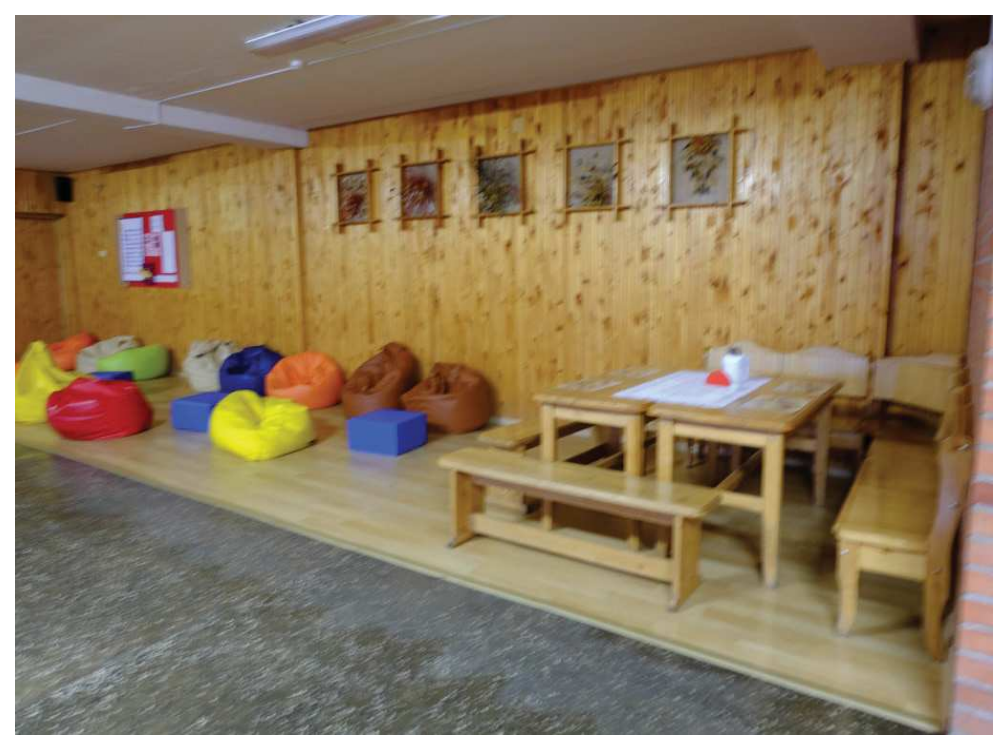

Figure 14. School canteen with beanbags which graduate pupils presented (S5) arrangement. In the second canteen (image 14) we see tables and benches that form a modular seating arrangement as well and there are beanbags next to the tables which are very beloved by the pupils. As McCorskey and McVetta (1978) stated, modular arrangement is advocated in classes in which student-student interaction is most important. Moreover "this arrangement permits maximum interaction among those groups while minimizing the interference of one group with another" (McCorskey and McVetta, 1987, p. 103). Even though these are school canteens, such an arrangement of tables and chairs might provide for pupils the opportunity to gather in small groups and form their territory and their circles; i.e., a group of friends, classes, etc. As pupils in the canteens usually can sit wherever they want, such a table position helps to gather together and communicate as they prefer. It is also important to mention that often in the school canteen teacher and pupil eating areas are separated: a rectangular table on the right side (next to the windows in image 13) is the teachers' eating place and the round tables are the pupils' eating tables. The separation of tables might divide the canteen into the pupils' territory and teachers' territory. Therefore, pupils in 'their' territory might feel more free, where, "You can see easily who (pupils -S. K.) are in a friendship with whom and even in couples. Here (canteen -S. K.) pupils even are not afraid to kiss each other" (S1-P). When considering Gordon and Lahelma's ideas it might be that a canteen in schools for some pupils is a space to get away from the attention and control of administration and teachers and have some privacy. Moreover, it is important to mention that in both schools $(S 1, S 5)$ the graduate class left presents - benches (S1) and beanbags (S5). These artifacts seem to help to strengthen the dependence on these places to pupils. One of the pupils (S5) during the walk commented about the graduate present tradition for schools: "I will be a graduate this year and I am thinking a lot about what to leave as a present for the gymnasium, what the gymnasium needs. I am thinking mostly 
of what the gymnasiums needs for the coming pupils so that they would be more comfortable here" (S5-P). So it seems that graduate pupils are concentrating their presents on pupils' needs and especially towards seating needs (S1, S2, S4, S5).

When we asked

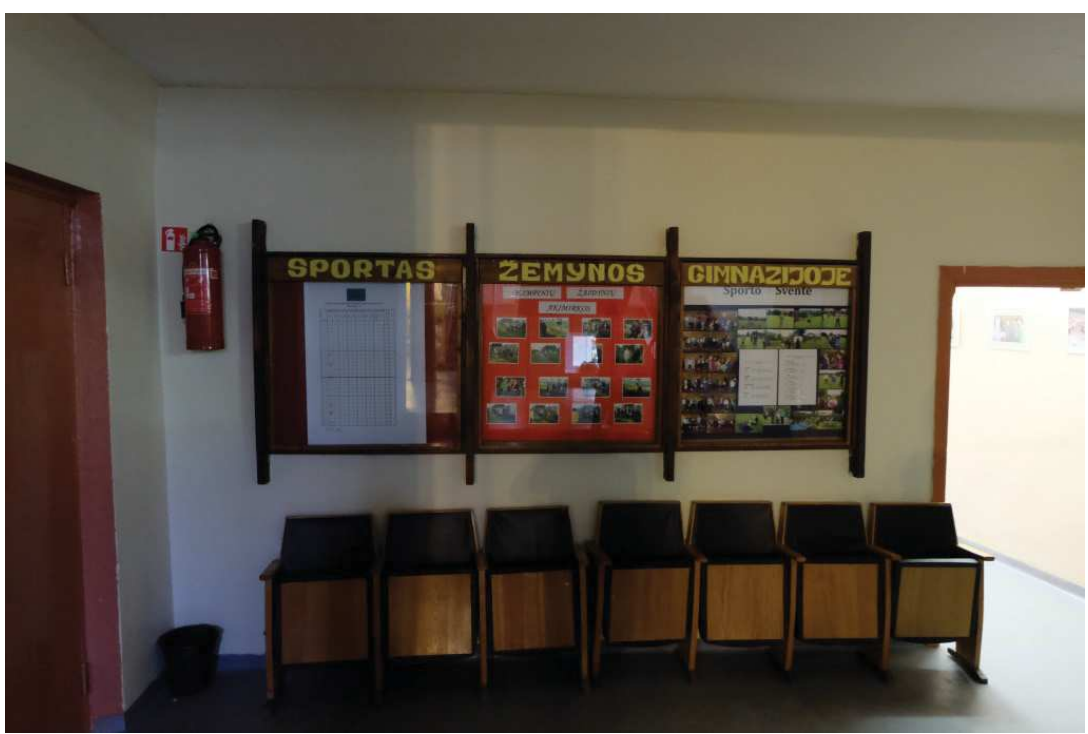

Figure 15. Information display in the school (S1) a pupil in the first school (S1) we walked with whether she likes to stay in the canteen, she said, "No, I don't like our canteen. The food is not good here. I eat in the corridor or in the school deputies' office. As I'm the member of the student council, I have the privilege to stay in that office" (image 9) (S1-P). A pupil from another school (S5) also said that now, "The youngest pupils always occupy the canteen" (S5-P). These extracts show that during breaks pupils have different places to gather and stay together. As was mentioned previously, it depends also on where the pupils belong, whether they are involved in some activities in schools, if they are members of the student council, have some activities after classes, etc. It is obvious that pupils in schools form their own sub-cultures (Prosser, 2007) so according to this it could be that the pupils' gathering places are also built and distributed according to the groups they belong to.

Even though there were many different displays in school hallways and corridors, like sport achievements, honored pupils, relevant information, in the school corridors pupils during walks paid little attention to them. In the first school the pupil showed only one information display (image below) next to the sport area.

As we see in the image (above), the information display is next to the places where pupils also like to sit during breaks. The pupil commented that before there was, "useful information, but nobody read it" (S1-P). It implies that the information displays are not that important for pupils. When we asked the pupil if she reads information in the information displays which are abundant in the school, the pupil answered: "Actually I rarely read information and advertisements in the school displays and I don't always notice that there is some information. One of the more important information displays for me is in the first floor (S.K. - informational display of student council). As a member of the student council last year I was also posting information there. Pupils are mostly interested in information about exams and some contests" (S1-P). 
This extract shows that pupils may follow the information in the school displays according to their interests. As the pupil said further: "I think that this information in displays and pupils' artwork are important for those who made them, but for others they aren't that important. Of course these things give some coziness to the school. It wouldn't be that cozy without it, but to look and go deep into it... I don't do it" (S1-P). Thus from one side, it might be that for pupils such artifacts as information displays and pupils' artwork function like decorations to create a cozy atmosphere in schools. Another pupil during the interview commented: "Mostly the class master tells us (pupils - S.K.) the important things.

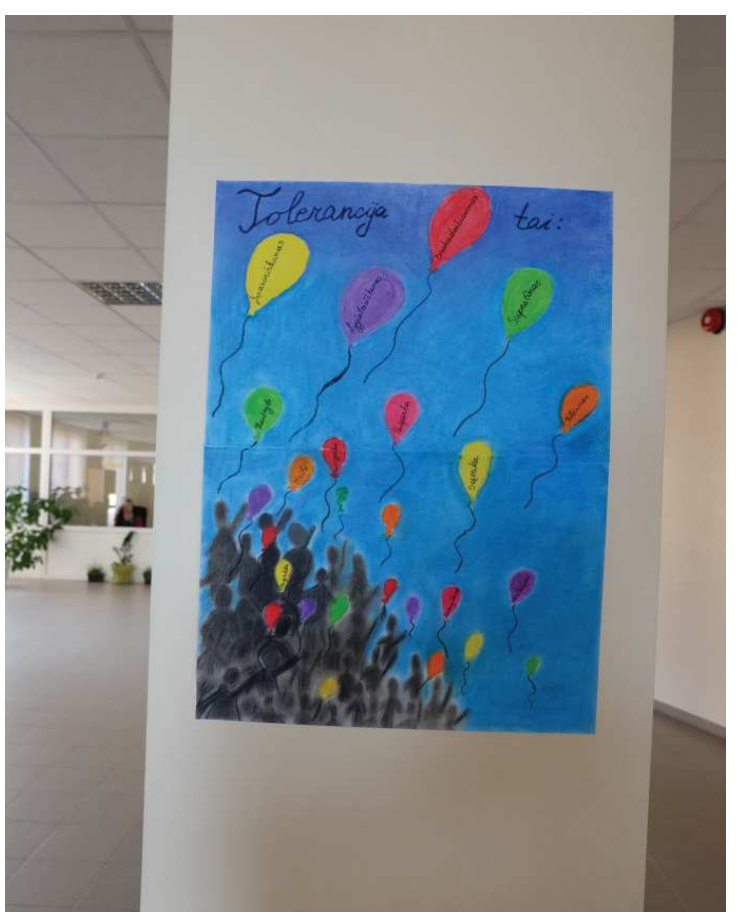

Figure 16. Poster made by pupils for Tolerance day (S2)

So somehow you do not look at information displays. I personally look at the information displays when I want to know the room number for assessments. There are electronic day-books and important information is always sent there. Or there is also a school website... so actually I do not really pay attention to information displays" (S1-P).

From this interview extract it seems that important information is transmitted in school by people or information technology. Thus the actual purpose of information displays to inform the school community actually changes and serves to make the school cozier or even may help to show to 'outsiders' that information in schools are spread out. From the other side, these artifacts might be meaningful for those pupils who contributed in creating the process or are mentioned in these artifacts. For example, in one school a pupil showed a poster for a Tolerance day (image 16) and mentioned that this poster was made by her and other pupils. In another school, a pupil showed an information display with penalties (image 17) and commented, "I will be here (in this display - S. K.) too because I don't wear a school uniform" (S6-P).

Walks with the pupils revealed the significance of non-teaching and non-learning places in schools where pupils can get out of the spotlight in one way or another and where it is comfortable for groups to gather. It is also important to note that pupils in the investigated schools are united in these places by certain sub-groups; for example, in the canteens $1^{\text {st }}$ and $2^{\text {nd }}$ class pupils $(S 1, S 5)$ often stay, in the deputies' office members of the student council and pupils responsible for contributing in event organization (S1, S5, S6) usually gather, in the entrance hall boys like to gather and they do not welcome 
girls to sit with them (S2), etc. Those artifacts, such as sofas, chairs, and beanbags, are indeed significant for pupils because they help to create private places and spaces for intercommunication and relationships among pupils. Seating plays an important role for pupils in all schools and is related to such meanings as privacy, personal territory, relaxation and social relations. As Prosser (2007) stated, non-teaching spaces in schools make an important contribution to school culture because they are

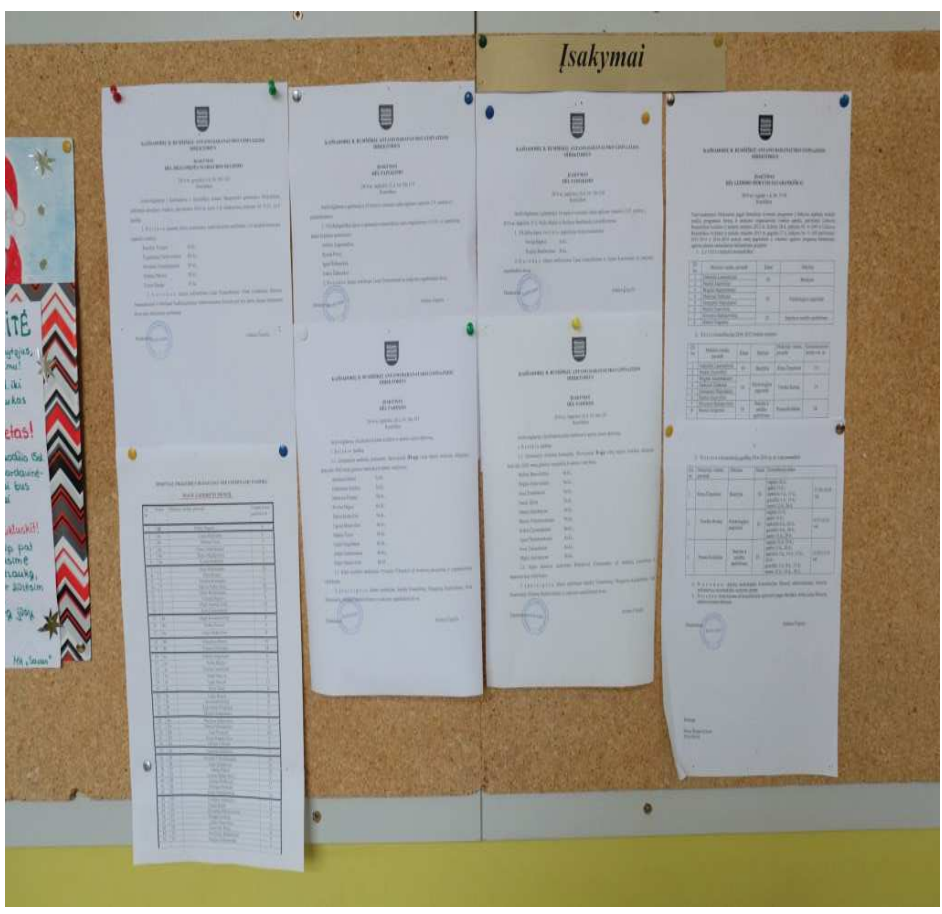

Figure 17. Information display with orders for penalties (S6) taken for granted and are deeply embedded in the teaching and learning behaviour of generations of teachers and pupils. Therefore, these places and artifacts that are there are integral parts of pupils' daily life in schools and are significant for them.

\section{CONCLUDING REMARKS}

This paper focused on significant artifacts and their meanings which were collected during walks with teachers and pupils in Lithuanian secondary schools. The analysis of visual data revealed that teachers and pupils in schools pay attention to different existing artifacts. In all schools teachers focused a lot of attention to artifacts related to school achievements and what pride meant, such as pupils' sport achievements, pupils' artworks, and displays with honored pupils. Aspects of pride might be important for different reasons: a long school history, a wish to show the uniqueness and exclusiveness of the school, or the influence of external evaluations in Lithuanian schools. Meanwhile, pupils during walks often remarked on spaces they like to gather and stay during non-learning time, like school hallways and less visible places in school corridors and canteens. Analysis showed that pupils appreciate places which are less visible and observable and where it is possible to get some privacy. It seems that different seating provision, for example, sofas, chairs, and beanbags, play an important role for creating pupils' places. It was quite visible even from graduate pupils' farewell presents, which in some schools were explicitly connected with seating meant for pupils. More- 
over, it seems that pupils do value other artifacts, like pupils' artworks and information displays, which in one way or another have a relation with pupils; i.e., in which they are mentioned, in whose creation they contributed, etc. Generally, it can be said that teachers tended to go into representational places and show representational objects and because of this it was difficult to understand what goes beyond visible things. On the other hand, pupils, even though most were members of the student council, were more open to show what is meaningful for them in everyday school life.

There may emerge some tension between teachers and pupils because these two groups create different meanings in schools. However, it is important to note that even though meanings that teachers give to artifacts may dominate, in a way pupils are allowed to create 'their territories' and to have those artifacts which are important for them.

Finally, the differences that were discovered among teachers and pupils suppose that school culture in these schools is a result of different interactions of existing subcultures. Considering Halls' (1997) idea that things in cultures rarely have single and fixed meaning, it is important to understand that because of different subcultures in schools there can also be no fixed meanings of existing artifacts. Therefore, the same artifacts for other members of the school community might have different meanings. These meanings might also change over the time.

\section{REFERENCES}

[1] Deal, E. D.; Peterson D. K. (2009). Shaping school culture. Pitfalls, paradoxes, and promises. San Francisco: Jossey-Bass.

[2] Gordon, T., Lahelma, E. (1996). School is like an ant's nest': spatiality and embodiment in schools. Gender and Education, 8(3), 301-310. doi: 10.1080/09540259621548

[3] Hall, S. (1997). Introduction, in S. Hall (Ed.), Representation: Cultural representations and signifying practices (pp. 1-12). London: Sage.

[4] Halverson, R. R. (2003). Systems of practice: how leaders use artifacts to create professional community in schools. Education Policy Analysis Archives, 11(37). Retrieved from http:/ / website.education.wisc.edu/halverson/wp-content/uploads/2012/09/v11n37.pdf

[5] Halverson, R. R. (2007). How leaders use artifacts to structure professional community of schools. In L. Stoll, K. Seashore Louis (Eds.), Professional learning communities: Divergence, depth and dilemmas (pp. 93-105). Maidenhead, UK: Open University Press.

[6] Happel, A. (2013). Ritualized girling: school uniforms and the compulsory performance of gender. Journal of Gender Studies, 22(1), 92-96. doi: 10.1080/09589236.2012.745680

[7] Hearn, H., Thomson, P. (2014). Working with texts, images and artefacts. In A. Clark, R. Flewitt, M. Hammersley, M. Robb (Eds.), Understanding research with children and young people (pp. 154-168). Los Angeles, CA: Sage.

[8] Huss, A. J. (2007). The role of school uniforms in creating an academically motivating climate: do uniforms influence teacher expectations? Journal of Ethnographic and Qualitative Research 2007, 1, 31-39. Retrieved from https://www.homeworkmarket.com/sites/default/files/ q2/18/12/article2.pdf

[9] McCorskey, C. J.; McVetta W.R. (1978). Classroom seating arrangements: instructional communication theory versus student preference. Communication Education, 27, 99-111. Retrieved from http:/ / www.jamescmccroskey.com/ publications/082.pdf

[10] National agency for school evaluation. External evaluation. Basic information (2015). Retrieved 
from http://www.nmva.smm.lt/external-evaluation-2/basic-information/

[11] O'Donaghue, D. (2006). Situating space and place in the making of masculinities in schools. Journal of Curriculum and Pedagogy, 3(1), 15-33. doi: 10.1080/15505170.2006.10411569.

[12] O'Donaghue, D. (2007). 'James always hangs out here': making space for place in studying masculinities at school. Journal of Visual Studies, 22(1), 62-73. doi: 10.1080/14725860601167218

[13] Prosser, J. (1999). The Evolution of School Culture Research. In J. Prosser (Ed.), School culture (pp. 1-14). London: Paul Chapman.

[14] Prosser, J. (2007). Visual methods and visual culture of schools. Visual Studies, 22(1), 13-30. doi: $10.1080 / 14725860601167143$

[15] Prosser J., Warburton T. (1999). Visual sociology and school culture. In J. Prosser (Ed.) School culture (pp. 82-97). London: Paul Chapman.

[16] Schein, E. H. (2010). Organizational culture and leadership (4th ed.). San Francisco, CA: Jossey-Bass.

[17] Survutaite, D. (2015). Unikalios kulturos mokykla [Unique school culture]. Svietimo problemos analize, 3(127). Retrieved from https://www.smm.lt/uploads/lawacts/docs/575_2ee579ef98 43cbbecdfacb0afa5c5158.pdf

[18] Webster's New Universal Unabridged Dictionary (1994). New Jersey: Barnes \& Noble Books. 